\title{
Aplicação de silício, em hidroponia, na conservação pós-colheita de alface americana 'Lucy Brown' minimamente processada
}

\author{
Silicon, in hydroponics, in postharvest American 'Lucy Brown' lettuce minimally processed
}

\author{
Vanessa Cury Galati ${ }^{I}$ João Emmanuel Ribeiro Guimarães ${ }^{I}$ Kelly Magalhães Marques \\ Joana Diniz Rosa Fernandes ${ }^{I}$ Arthur Bernardes Cecílio Filho ${ }^{I}$ Ben-Hur Mattiuz ${ }^{I^{*}}$
}

\section{RESUMO}

Este trabalho teve por objetivo verificar o efeito da aplicação de silício em hidroponia na conservação pós-colheita de alface americana 'Lucy Brown' minimamente processada. As alfaces foram cultivadas hidroponicamente e a fonte de silicio utilizada foi o silicato de potássio nas concentrações de 0; 28; 56; e 84mg $L^{-1}$. Após a colheita, as folhas selecionadas foram lavadas em água corrente, semiprocessadas mediante o corte de $20 \mathrm{~mm}$ de largura e sanitizadas por imersão em Sumaveg ${ }^{\circledR}$. Estas foram centrifugadas manualmente e acondicionadas em sacos de polipropileno, que, posteriormente, foram selados $e$ armazenados a $3{ }^{\circ} \mathrm{C}$ e $85 \pm 3 \%$ de umidade relativa (UR). Durante 16 dias de armazenamento, foram avaliadas a cada quatro dias e em triplicata, a composição gasosa, a firmeza, o teor de clorofila e de acidez titulável, as atividades das enzimas polifenoloxidase $e$ peroxidase e as análises microbiológicas. Até o 4ódia de armazenamento, observaram-se reduções nos niveis de $\mathrm{O}_{2}$ para todos os tratamentos, no entanto, para os niveis de $\mathrm{CO}_{2}$, houve aumentos percentuais de $5 \%$ no tratamento com $28 \mathrm{mg} \mathrm{L}^{-1}$ de silício. As maiores concentrações de silício mantiveram maior firmeza das folhas. Os teores de clorofila total se mantiveram estáveis durante o periodo de armazenamento. A atividade da enzima polifenoloxidase reduziu até o $8^{\circ}$ dia. A atividade da peroxidase apresentou aumento durante o periodo avaliado, na concentração de $84 \mathrm{mg} \mathrm{L}^{-1}$ de silício. A contagem microbiana de coliformes termotolerantes e totais manteve-se baixa durante o armazenamento. A concentração de $84 \mathrm{mg}^{L^{-1}}$ de silicio propiciou maior firmeza das folhas das alfaces minimamente processadas, deixando-as mais túrgidas e conservando sua vida útil por 16 dias.

Palavras-chave: Lactuca sativa, adubação silicatada, conservação pós-colheita.

\section{ABSTRACT}

This study aimed to verify the effect of silicon in hydroponics in postharvest of american 'Lucy Brown' lettuce minimally processed. Lettuces were grown hydroponically and silicon source used was potassium silicate at concentrations of 0, 28, 56 and 84mg $L^{-1}$. After harvesting, the selected leaves were washed in tap water, and semiprocessed by cutting leaves $20 \mathrm{~mm}$ wide, immersed in solutions Sumaveg ${ }^{\circledR}$. These leaves were centrifuged manually and packed in polypropylene bags, after, were sealed and stored at $3{ }^{\circ} \mathrm{C}$ and $85 \pm 3 \%$ of relative humidity (RH). During 16 days of storage, leaves were evaluated every four days and in triplicate, gas composition, firmness, chlorophyll content and titratable acidity, activities polyphenol oxidase activities and peroxidase enzymes and microbiological analyzes. By the $4^{\text {th }}$ day storage it was observed reductions in $\mathrm{O}_{2}$ levels for all treatments. However, for levels of $\mathrm{CO}_{2}$, it was observed an increased percentage of $5 \%$ in the treatment with $28 \mathrm{mg} \mathrm{L^{-1 }}$ of silicon. The highest concentrations of silicon in the leaves mantained higher firmness. Total chlorophyll remained stable during the storage period. Enzyme polyphenoloxidase activity reduced until the $8^{\text {th }}$ day. Peroxidase activity showed an increase during the study period at a concentration of $84 \mathrm{mg} \mathrm{L}^{-1}$ silicon. Microbial counts of thermotolerant coliforms remained low during storage. A concentration of $84 \mathrm{mg} \mathrm{L}^{-1}$ silicon provided greater firmness of minimally processed leaves of lettuce making them more turgid and preserving its useful life for 16 days.

Key words: Lactuca sativa, silicon fertilization, postharvest conservation.

\section{INTRODUÇÃO}

A alface é considerada a hortaliça folhosa mais comercializada e consumida pelos brasileiros, pois sua produção se estende durante todo o ano e é facilmente adquirida (OLIVEIRA et al., 2004). Em 2012, a CEAGESP comercializou 30.188 toneladas de alface (AGRIANUAL, 2013).

\footnotetext{
'Departamento de Tecnologia, Faculdade de Ciências Agrárias e Veterinárias (FCAV), Universidade Estadual Paulista "Julio de Mesquita Filho" (UNESP), Via de Acesso Prof. Paulo Donato Castellane, s/n, 14884-900, Jaboticabal, SP, Brasil. E-mail: benhur@fcav.unesp.br. *Autor para correspondência.
} 
O sucesso das hortaliças minimamente processadas deve-se, em grande parte, à conveniência que esses produtos oferecem ao consumidor, por estarem prontos para o consumo, aliados à segurança microbiológica (ZAGORY, 2000). No entanto, a alface minimamente processada pode apresentar vários efeitos indesejáveis, como perda da cor verde ou amarelecimento, escurecimento da superfície cortada e perda de turgidez (CHITARRA \& CHITARRA, 2007).

Dentre as práticas culturais, a adubação mineral exerce forte influência na qualidade e na conservação dos vegetais após sua colheita, interferindo tanto nos processos de respiração e transpiração quanto à composição química, aparência interna e externa, estruturas anatômicas, processos degradativos e sabor dos vegetais (MATTIUZ, 2007).

Formulações alternativas para o cultivo hidropônico vêm sendo estudadas, com destaque para a adição de silício ( $\mathrm{Si}$ ), que demonstra potencial na redução de doenças e anomalias fisiológicas, e, por isso, tem sido utilizado com o intuito de aumentar a produção e manter a integridade das células. $\mathrm{O}$ silício atua no mecanismo da transpiração, e o acúmulo desse nutriente nos órgãos ocorre pela formação de uma camada dupla de sílica cuticular, contribuindo, assim, para a redução da perda de água durante o período de armazenamento do produto minimamente processado (KORNDORFER et al., 2004). Atua também na parte estrutural, na síntese de hemicelulose e lignina presentes nas paredes celulares, que deixam as células mais rígidas e, consequentemente, aumentam a firmeza das folhas de alfaces (BARBOSA FILHO et al., 2001).

Este trabalho teve por objetivo verificar o efeito da aplicação de silício em hidroponia na conservação pós-colheita de alface americana 'Lucy Brown' minimamente processada.

\section{MATERIAL E MÉTODOS}

Plantas de alfaces 'Lucy Brown', pertencentes ao grupo americana, foram cultivadas hidroponicamente, na UNESP, Campus de Jaboticabal, SP, utilizando a Nutrient Film Technique (NFT). Como fonte de silício, adicionou-se, na solução nutritiva, silicato de potássio nas concentrações de $0 ; 28 ; 56$ e $84 \mathrm{mg} \mathrm{L}^{-1}$. A semeadura foi realizada em espuma fenólica, com dimensões de $2 \times 2 \times 2 \mathrm{~cm}$, contendo uma plântula por célula e colocadas em casa de vegetação para germinação e emergência. Cerca de 10 dias após a emergência, as mudas foram transferidas para o berçário, permanecendo em canais hidropônicos (NFT) por 13 dias, sendo então transplantadas para os canais de crescimento, também em NFT, para receberem os tratamentos com doses crescentes de silício.
A colheita das alfaces foi realizada 58 dias após a semeadura, aproximadamente às 6 horas da manhã, quando as plantas estavam com a cabeça completamente fechada e compacta. Após a colheita, as plantas foram transportadas para o Laboratório de Tecnologia dos Produtos Agrícolas, do Departamento de Tecnologia, na UNESP, Campus de Jaboticabal. Partes danificadas ou com podridão foram eliminadas e o lote homogeneizado. As folhas apresentavam coloração externa verde escura e interna verde mais clara. As folhas selecionadas foram lavadas com água corrente para retirada de impurezas aderidas ao vegetal. Em seguida, em câmara fria a $8^{\circ} \mathrm{C}$, as alfaces foram processadas mediante o corte das folhas em tiras com $20 \mathrm{~mm}$ de largura, transversalmente à nervura central. Na sequência, fez-se imersão do produto em solução resfriada de Sumaveg ${ }^{\circledR}$, a $150 \mathrm{mg} \mathrm{L}^{-1}$ de cloro livre, por 10 minutos, com a finalidade de sanitizar e de retirar o suco resultante do extravasamento celular. Para retirada do excesso de cloro, foi realizada uma segunda imersão em Sumaveg ${ }^{\circledR}$, a $10 \mathrm{mg} \mathrm{L}^{-1}$ de cloro livre, na temperatura de $5^{\circ} \mathrm{C}$. Posteriormente, o excesso de água do produto foi retirado por centrifugação manual. $\mathrm{O}$ produto minimamente processado foi acondicionado em sacos de polipropileno de $30 \mathrm{~cm}$ de comprimento x $40 \mathrm{~cm}$ de largura e $60 \mu \mathrm{m}$ de espessura, contendo, aproximadamente, 200 gramas de alface em cada, os quais foram selados e armazenados em expositores, a $3^{\circ} \mathrm{C}$ e $85 \pm 3 \%$ de umidade relativa, por 16 dias.

O delineamento utilizado foi o inteiramente casualizado, em esquema fatorial $(4 \mathrm{x} 4)$, sendo composto por quatro tratamentos (concentrações de silício: 0, 28, 56 e $84 \mathrm{mg} \mathrm{L}^{-1}$ ) e quatro dias de avaliações (dias $0,4,8$, 12 e 16), com três repetições por tratamento.

Durante o período de armazenamento, foram avaliadas as evoluções do $\mathrm{O}_{2}$ e $\mathrm{CO}_{2}$ no interior das embalagens, com auxílio de um analisador de gases (PBI-Dansensor 9900); a firmeza, de acordo com metodologia descrita por CALBO et al. (2010); a acidez titulável, conforme a AOAC (1997); o teor de clorofila total, segundo ARNON (1949); as atividades das enzimas polifenoloxidase e peroxidase (ADNAN et al., 1986; MATSUNO \& URITANI, 1972) e as análises microbiológicas de microrganismos mesófilos, coliformes totais e termotolerantes (APHA, 2001). Os resultados foram submetidos à análise de variância (ANOVA) utilizando o software SAS (SAS Institute Inc.) e o efeito dos tratamentos, quando significativo, por meio do Teste $F$. Diferenças significativas entre os resultados foram comparadas usando diferença mínima significativa (DMS), com 95\% de intervalo de confiança $(P \leq 0,05)$ (STEEL \& TORRIE 1987). 


\section{RESULTADOS E DISCUSSÃO}

Durante o período de armazenamento, ocorreram variações na taxa respiratória das alfaces minimamente processadas. De acordo com a figura $1 \mathrm{~A}$, até o $4^{\circ}$ dia de armazenamento, no interior das embalagens, detectaram-se reduções nos níveis de $\mathrm{O}_{2}$ em todos os tratamentos. As maiores reduções percentuais, sem diferenças significativas entre os tratamentos, foram notadas nos tratamentos de $28 \mathrm{mg}$ $\mathrm{L}^{-1}(7 \%), 56 \mathrm{mg} \mathrm{L}^{-1}(5 \%)$ e $84 \mathrm{mg} \mathrm{L}^{-1}(3 \%)$ e a menor redução $(1 \%)$ no tratamento controle. Em relação aos níveis de $\mathrm{CO}_{2}$, houve aumentos percentuais de $5 \%$ no tratamento $28 \mathrm{mg} \mathrm{L}^{-1}$ sem apresentar diferenças significativas, em relação ao tratamento $56 \mathrm{mg} \mathrm{L}^{-1}$ (4\%) (Figura 1). Uma das principais manifestações fisiológicas provenientes da ruptura de tecidos vegetais é o aumento da taxa de respiração. Dessa forma, alterações nas concentrações de $\mathrm{O}_{2}$ e $\mathrm{CO}_{2}$ podem ter ocorrido devido às respostas fisiológicas induzidas pelas injúrias mecânicas causadas pelo processamento mínimo. Os resultados observados neste estudo estão de acordo com os encontrados por MATTOS (2005), ao verificar que, em alfaces minimamente processadas, ocorreu aumento na atividade respiratória após o processamento mínimo.

A alteração na taxa respiratória foi maior nos vegetais que tiveram aplicação de silício, com destaque para a concentração de $28 \mathrm{mg} \mathrm{L}^{-1}$. Isso pode estar relacionado ao fato de o silício encontrarse mais presente nas paredes dos estômatos e nas células epidérmicas das alfaces que receberam o tratamento, fazendo com que ocorresse, ao longo do armazenamento, a manutenção da integridade das células. Com isso, o processo respiratório manteve-se mais elevado, uma vez que as células estavam mais ativas e túrgidas, aumentando, a atividade enzimática desses vegetais, quando comparado aos que não receberam doses de silício ou àqueles que o receberam em menores quantidades. Os resultados observados estão de acordo com os obtidos por DELLA COLLETA (2009), que verificou aumento nos níveis de $\mathrm{CO}_{2}$ até o $4^{\circ}$ dia de armazenamento, com posterior redução até o $10^{\circ}$ dia em cenouras, repolhos roxos e couves minimamente processados, acondicionados em embalagens de polietileno de alta densidade (PEAD).

A firmeza foi afetada significativamente pelo tempo, havendo diminuição em todos os tratamentos. Entretanto, observou-se maior firmeza nas folhas de alface,proporcional à concentração de silício aplicada (Figura 2A). As alfaces que receberam o tratamento com $84 \mathrm{mg} \mathrm{L}^{-1}$ de silício apresentaram firmeza de, aproximadamente, $280 \mathrm{kgf}^{2}$ no $16^{\circ}$ dia após o armazenamento, enquanto que o tratamento controle apresentou um valor aproximado de $140 \mathrm{kgf}$ $\mathrm{cm}^{2}$, indicando a manutenção da integridade das células das plantas tratadas com silício. A medição da firmeza fornece um indicativo das transformações na estrutura celular, coesão das células e alterações bioquímicas responsáveis pela textura do produto. $\mathrm{O}$ silício se caracteriza por fazer parte da estrutura da planta, sua presença na parede celular pode aumentar o conteúdo de hemicelulose e de lignina, aumentando a rigidez da célula. Assim, o tratamento com silício reduz a transpiração, mantém a célula mais túrgida e, consequentemente, a firmeza das folhas, prolongando o período de armazenamento (BARBOSA FILHO et al., 2001; KIM et al., 2002).

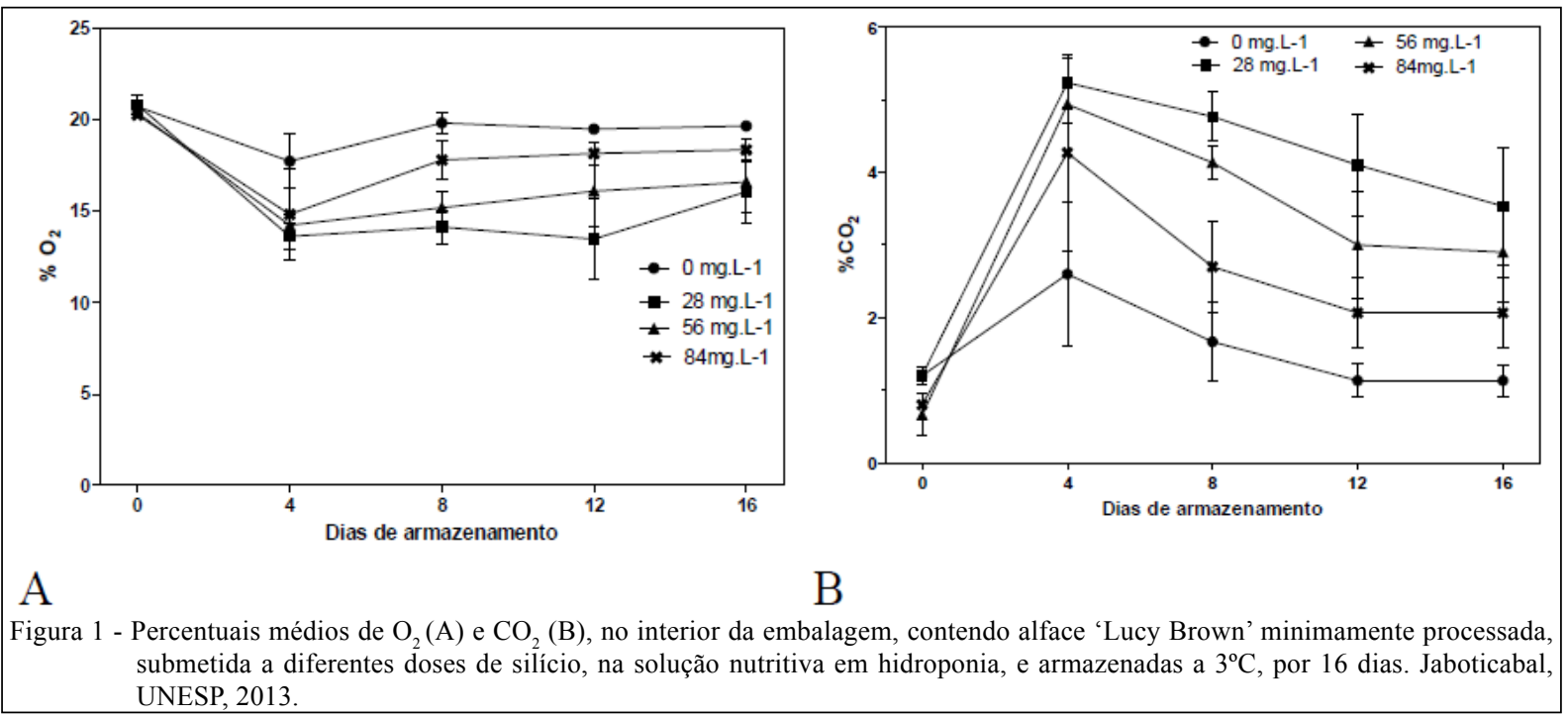

Ciência Rural, v.45, n.11, nov, 2015. 


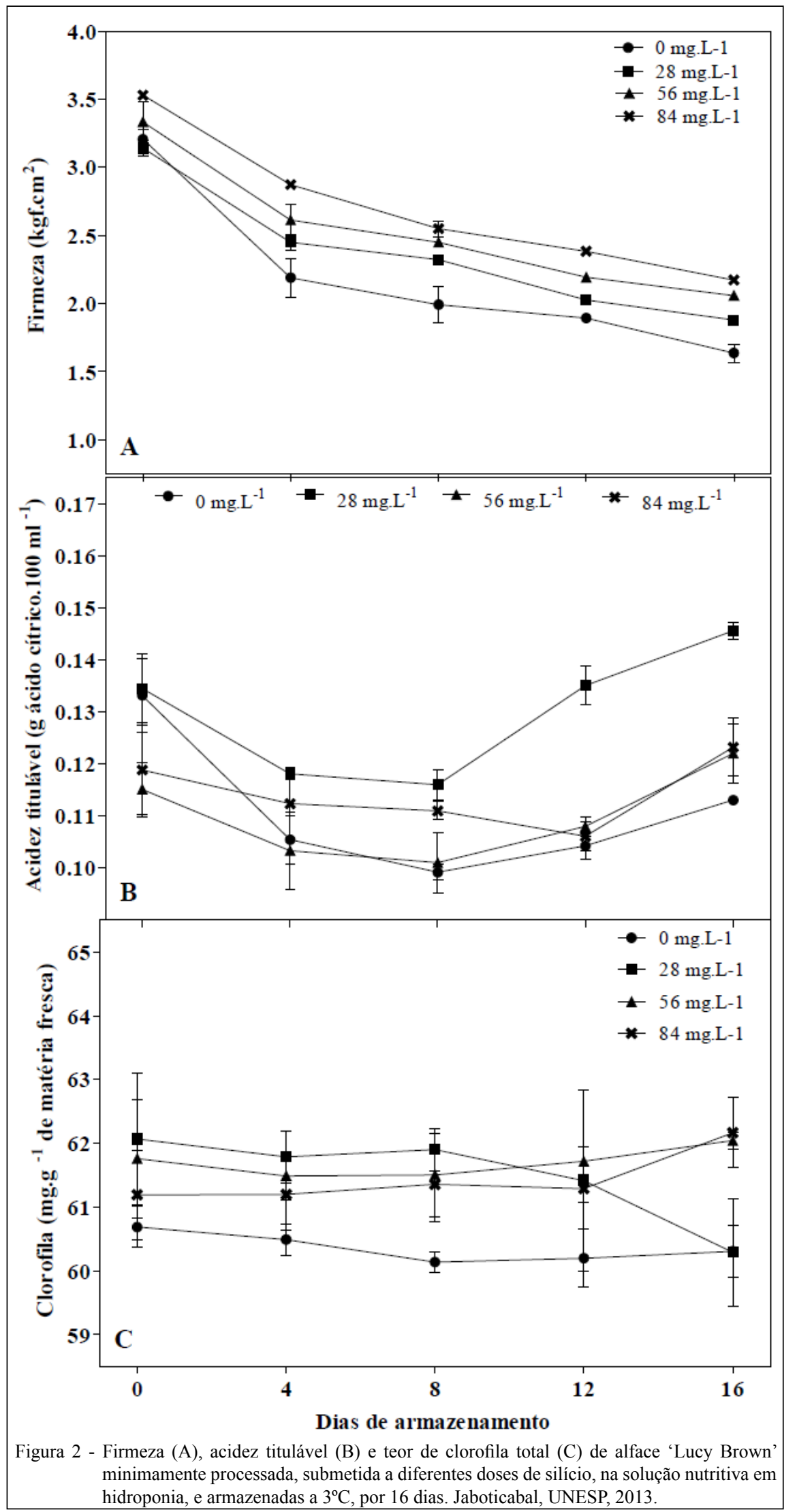

Ciência Rural, v.45, n.11, nov, 2015. 
O estresse causado no vegetal devido ao corte no processamento mínimo contribui para as mudanças da atividade enzimática da parede celular e alterações no pH (FISCHER\& BENNETT, 1991). No decorrer do período de armazenamento, houve redução no teor de ácidos orgânicos (Figura 2B). A redução da acidez titulável em produtos minimamente processados ocorre em consequência do metabolismo normal do $\mathrm{CO}_{2}$, ou em resposta do tecido, ao neutralizar a acidez gerada pelo $\mathrm{CO}_{2}$ durante o processo respiratório (KADER, 1986). MATTOS (2005) observou, em alfaces minimamente processadas, tendência na redução do teor de ácidos orgânicos durante o período experimental, uma vez que estes ácidos podem ser utilizados como substrato na respiração, apresentando resultados semelhantes aos encontrados neste trabalho.

Entretanto, a partir do $8^{\circ}$ dia de armazenamento, observou-se aumento da acidez, principalmente para o tratamento com $28 \mathrm{mg} \mathrm{L}^{-1}$ de silício, que apresentou $140 \mathrm{mg}$ de ácido cítrico $100 \mathrm{~g}^{-1}$ de matéria fresca, enquanto que o controle apresentou valores médios de $114 \mathrm{mg}$ de ácido cítrico $100 \mathrm{~g}^{-1}$ de matéria fresca, no $16^{\circ}$ dia de armazenamento (Figura 2B). As alfaces tratadas com silício apresentaram maior quantidade de água (mais túrgidas) em suas células, quando comparados aos outros tratamentos. Nessas células, houve maior produção de $\mathrm{CO}_{2}$ e este, por sua vez, pode ter reagido com a água, formando ácido carbônico, culminando no aumento da acidez. Além disso, CHITARRA\&CHITARRA (2005) ressaltam o caráter acídico dos compostos fenólicos, por apresentarem hidrogênio em seu grupamento hidroxílico, fazendo com que este grupo se desprenda por ionização quando em contato com a água, podendo contribuir para a elevação da acidez durante o período de armazenamento. Isso está de acordo com os resultados obtidos neste experimento, ao verificar aumento nas atividades das enzimas polifenoloxidase e peroxidase a partir do $8^{\circ}$ dia de armazenamento.

Os teores de clorofila totais se mantiveram estáveis durante o período de armazenamento, entretanto, o tratamento controle apresentou as menores médias (60 $\mathrm{mg} \mathrm{g}^{-1}$ de matéria fresca), não diferindo estatisticamente dos demais tratamentos (Figura 2C). Ficou evidente que a degradação da clorofila, durante os 16 dias de armazenamento, foi baixa, o que contribuiu para a manutenção da cor verde nas folhas das alfaces, que se encontravam aptas para o consumo, até o final do armazenamento.

A baixa temperatura de armazenamento $\left(3^{\circ} \mathrm{C}\right)$ também deve ter contribuído para evitar a degradação desse pigmento, pois diminuiu o metabolismo foliar e, consequentemente, controla os processos degradativos e a senescência das folhas (HEATON \& MARANGONI, 1996). CARNELOSSI et al. (2002) também constataram em embalagens de baixa permeabilidade, a $1^{\circ} \mathrm{C}$ e $5^{\circ} \mathrm{C}$, que os teores de clorofila totais, em couve minimamente processada, se mantiveram constantes durante o período de armazenamento.

A atmosfera modificada, em virtude dos seus efeitos inibitórios no metabolismo, também deve ter contribuído para a manutenção dos teores de clorofila totais. Isso indica que a redução dos níveis de $\mathrm{O}_{2}$ e o aumento do $\mathrm{CO}_{2}$ na atmosfera que envolve os produtos frescos é a alternativa para promover a retenção de clorofila e outros pigmentos durante o período de estocagem (MANTILLA et al., 2010). Ao analisar plantas de Valerianella locusta cultivadas em meio hidropônico, GOTTARDI et al. (2012) também observaram manutenção do teor de clorofiladas plantas, cujas soluções continham silício, o que retardou a senescência foliar e prolongou a vida útil do vegetal.

Entretanto, destaca-se que a polifenoloxidase (PPO) e a peroxidase (POD) respondem a condições de estresse, e estão envolvidas no mecanismo de defesa do vegetal. Dessa forma, alterações nas atividades da PPO e POD podem ocorrer durante todo o armazenamento de produtos minimamente processados, pois há associação entre a senescência e o escurecimento dos tecidos. Houve redução da atividade da PPO até o $8^{\circ}$ dia de armazenamento, com consequente incremento nos valores, principalmente para a concentração de $84 \mathrm{mgL}^{-1}$ (Figura 3A). O aumento da atividade da PPO pode estar relacionado a uma situação de estresse, devido ao corte das folhas por ocasião do processamento, o que ocasionou a perda de integridade celular na superfície cortada, colocando em contato enzimas e seus substratos que até então estavam em compartimentos celulares separados, o que acelerou o metabolismo do vegetal (SOARES et al., 2004; MATTOS et al., 2007). Ademais, observaseque a utilização do silício em hidroponia não foi capaz de diminuir tal estresse, uma vez que as alfaces tratadas com maiores concentrações de silício apresentaram atividades da PPO mais elevadas.

FAWE et al. (1998) demonstraram pela primeira vez, em pepinos, que plantas tratadas com silício também apresentaram aumento na atividade das enzimas polifenoloxidase, peroxidase, quitinases, fitoalexinas e flavonóides, o que ocasionou a proteção desses vegetais.

Segundo MORETTI (2007), o processamento mínimo de um vegetal promove o 


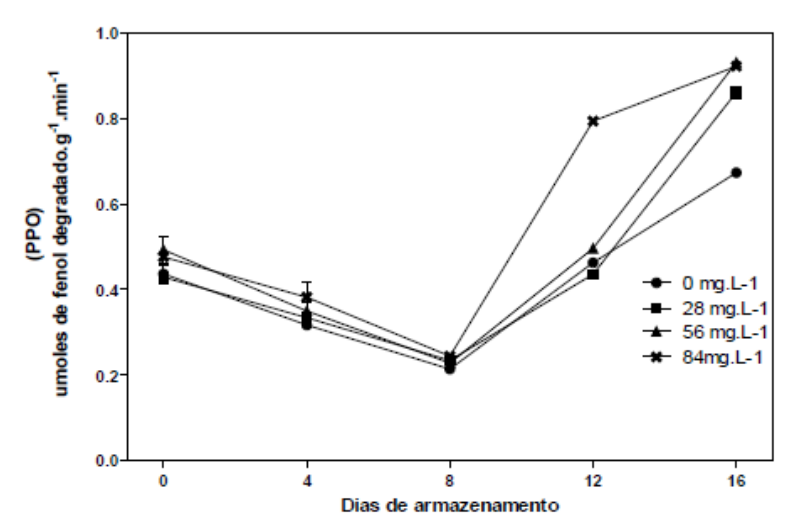

A

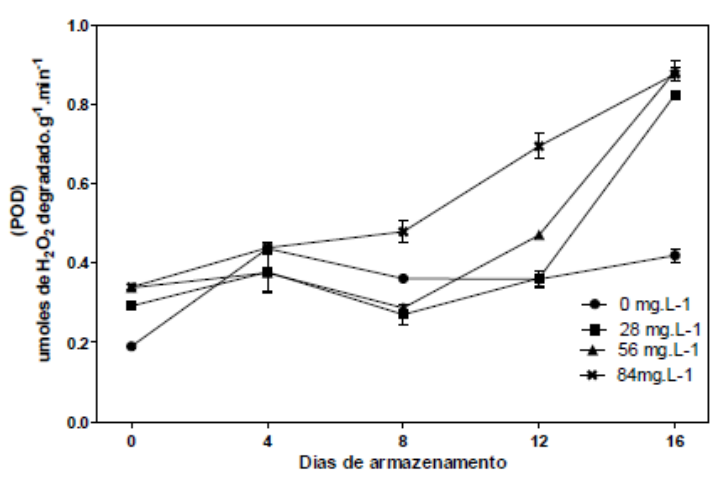

B

Figura 3 - Atividades das enzimas polifenoloxidase (PPO) em (A) e peroxidase (POD) em (B) de alface 'Lucy Brown' minimamente processada, submetida a diferentes doses de silício, na solução nutritiva em hidroponia, e armazenadas a $3^{\circ} \mathrm{C}$, por 16 dias. Jaboticabal, UNESP, 2013.

aumento da respiração, da produção de etileno e indução e síntese de compostos fenólicos para a cicatrização dos tecidos. Além disso, acarreta o extravasamento de substratos fenólicos do vacúolo, que entram em contato com as enzimas catalisadoras das reações de oxidação dos polifenóis (polifenoloxidase) presentes no citoplasma, formando as melaninas, que resultam no escurecimento enzimático (JACOMINO et al., 2008; ALENCAR\&KOBLITZ, 2008). De maneira similar ao que foi observado para a PPO, as atividades da POD mais elevadas foram verificadas nas folhas de alface cultivadas em meio hidropônico com maiores concentrações de silício. Contudo, observa-se, que a atividade enzimática da peroxidase (POD) apresentou um aumento constante para concentração de $84 \mathrm{mg} \mathrm{L}^{-1}$ de silício, devido à manutenção da integridade da célula, provavelmente, pela aplicação de silício na solução hidropônica (Figura 3B). A enzima POD é capaz de catalisar a oxidação de componentes celulares, tais como peróxido de hidrogênio ou peróxidos orgânicos. Em vegetais, este grupo de enzimas constitui proteção antioxidativa, podendo ocorrer aumento dessa atividade quando a planta for submetida a diversos tipos de estresse (SIEGEL, 1993).

As contagens dos microrganismos mesófilos no $16^{\circ}$ dia de armazenamento se mantiveram baixas, porém foram maiores do que no início do armazenamento. Verificou-se, também que, para a concentração de $28 \mathrm{mgL}^{-1}$ de silício, os valores obtidos foram superiores aos demais tratamentos. Os coliformes termotolerantes e totais a $45^{\circ} \mathrm{C}$, no início e no final do armazenamento, apresentaram contagens muito baixas $\left(<3,0 \mathrm{NMP} \mathrm{g}^{-1}\right)$, exceto para o tratamento com $56 \mathrm{mg} \mathrm{L}^{-1}$ de silício, que possui 4NMP $\mathrm{g}^{-1}$ no início do armazenamento. Entretanto, mesmo sendo superior aos observados nas demais concentrações de silício, este valor ainda é considerado baixo. A baixa contaminação microbiana encontrada neste trabalho deve-se, principalmente, aos cuidados higiênico-sanitários tomados durante o processamento, armazenamento e manipulação adequada dos produtos.

\section{CONCLUSÃO}

A concentração de $84 \mathrm{mg} \mathrm{L}^{-1}$ de silício propiciou maior firmeza das folhas das alfaces minimamente processadas, deixando-as mais túrgidas e conservando sua vida útil por 16 dias.

\section{AGRADECIMENTOS}

Ao Conselho Nacional de Desenvolvimento Científico e Tecnológico (CNPq), pelo auxílio na forma de bolsa de Doutorado (processo 140194/2011-8).

\section{REFERÊNCIAS}

ADNAN, T.A.B.T.et al. Polyfenoloxydase from star fruit. Pertanika, v.9, n.2, p.219-224, 1986.

AGRIANUAL 2013: anuário da agricultura brasileira. São Paulo: FNP Consultoria, 2012.143p.

ALENCAR, S.M.; KOBLITZ, M.G.B. Oxirredutases. In: KOBLITZ, M.G.B. (Coord.). Bioquímica de alimentos. Rio de Janeiro, Guanabara Koogan, 2008. p.125-152.

AOAC. Official methods of analysis of the Association of Official Analytical Chemists International.16.ed.Washington: Patrícia Cunniff, 1997. v.2, 850p. 
APHA. Committee on microbiological methodos for foods. In: Compendium of methods for the microbiological examination of foods. 3.ed. Washington: American Public Health Association, 2001. 1219p.

ARNON, D.I. Copper enzymes in isolated chloroplasts: polyphenoloxydase in Beta vulgaris. Plant Physiology, v.24, n.1, p.1-15, 1949

BARBOSA FILHO, M.P. et al. Silicato de cálcio como fonte de silício para arroz de sequeiro. Revista Brasileira de Ciência do Solo, v.25, p.325-330, 2001. Disponível em: $<$ http://www.scielo.br/scielo.php?script=sci arttext\&pid $=$ S1413-70542004000200011 $>$. Acesso em: 01 ago. 2012. doi: $10.1590 / \mathrm{S} 1413-70542004000200011$

CALBO, A.G. et al. A leaf lamina compression method for estimating turgor pressure. Hortscience, 45, n.3, p.418-423, 2010. Disponível em: <http://hortsci.ashspublications.org/cgi/ reprint/45/3/418>. Acesso em: 14 nov. 2014

CARNELOSSI, M.A.G.et al. Conservação de folhas de couve minimamente processadas. Revista Brasileira de Produtos Agroindustriais, v.4, n.2, p.149-155, 2002. Disponível em: <http:// www.deag.ufcg.edu.br/rbpa/rev42/Art427.pdf $>$. Acesso em: 03 jun. 2013. doi: 10.1590/S0102-05362005000200011.

CHITARRA, M.I.F.; CHITARRA, A.B. Pós-colheita de frutos e hortaliças: fisiologia e manuseio. 2.ed. rev. e ampl. Lavras: UFLA, 2005. 421p

CHITARRA, M.I.F.; CHITARRA, A.B. Processamento mínimo de alface. In: MORETTI, C.L. (Eds.). Manual de processamento mínimo de frutas e hortaliças. Brasília: Embrapa hortaliças e SEBRAE, 2007. p.301-341.

DELLA COLLETA, R.C.L. Respostas fisiológicas de cenoura, repolho roxo e couve minimamente processados isolados e em combinação. 2009. 69p. Dissertação (Mestrado em Fisiologia Vegetal) - Universidade Federal de Viçosa, MG.

FAWE, A. et al. Silicon mediated accumulation of flaninoid phytoalexins in cucumber. Phytopatholigy, v.88, p.396-401, 1998 Disponível em: $<$ http://dx.doi.org/10.1094/PHYTO.1998.88.5.396>. Acesso em: mar. 2013. doi: 10.1094/PHYTO.1998.88.5.396.

FISCHER, R.L.; BENNETT, A.B. Role of cell wall hydrolases in fruit ripening. Annual Review of Plant Physiology and Plant Molecular Biology, v.42, p.675-703, 1991. Disponível em: <http://www. annualreviews.org/doi/pdf/10.1146/annurev.pp.42.060191.003331>. Acesso em: 25 maio 2013. doi: 10.1146/annurev.pp.42.060191.003331.

GOTTARDI, S.et al. Beneficial effects of silicon on hydroponically grown corn salad (Valerianella locusta (L.) Laterr) plants. Plant Physiology and Biochemistry v.56, p.14-23, 2012. Disponível em: <http://www.ncbi.nlm.nih.gov/pubmed/22579940>. Acesso em: 30 maio 2013. doi: 10.1016/j.plaphy.2012.04.002.

HEATON, J.W.;MARANGONI, A.G. Chlorophyll degradation in processed foods and senescent plant tissues. Trends Food Science Technology, v.7, p.8-15,1996. Disponível em: <http://ac.els-cdn. com/0924224496813525/1-s2.0-0924224496813525-main.pdf? $\mathrm{tid}=6 \mathrm{c} 42 \mathrm{~d} 9 \mathrm{~d} 4-20 \mathrm{~d} 7-11 \mathrm{e} 5-\mathrm{b} 62 \mathrm{a}-00000 \mathrm{aacb} 361 \& \mathrm{acdnat}=1435854711$ cd9fb4549a48394865fd223b92b3355f >. Acesso em: 08 nov. 2012. doi: $10.1016 / 0924-2244(96) 81352-5$.
JACOMINO, A.P.et al. Transformações bioquímicas em hortícolas após a colheita. In: KOBLITZ, M.G.B. (Coord.). Bioquímica de alimentos. Rio de Janeiro: Guanabara Koogan, 2008. p.153-189.

KADER, A.A. Biochemical and physiological basis for effects of controlled and modified atmospheres on fruits and vegetables. Food Tecnology, v.40,n.5, p.99-104, 1986.

KIM, S.G.et al. Silicon-induced cell wall fortification of rice leaves: a possible cellular mechanism of enhanced host resistance to blast. Phytopathology, v.92, p.1095-1103, 2002. Disponível em: <http://apsjournals.apsnet.org/doi/pdf/10.1094/ PHYTO.2002.92.10.1095>. Acesso em: 02 jun. 2013. doi: 10.1094/PHYTO.2002.92.10.1095

MANTILLA, S.P.S. et al. Atmosfera modificada na conservação de alimentos. Revista Acadêmica, Ciências Agrárias Ambientais, v.8, n.4, p.437-448, 2010.

MATSUNO, H.; URITANI, I. Physiological behavior of peroxidase isozymes in sweet potato root tissue injured by cutting or with black rot. Plant and Cell Physiology, v.13, p.1091-1101, 1972

MATTIUZ, B.H. Fatores da pré-colheita influenciam a qualidade final dos produtos. Revista Visão Agrícola, n.7, p.18-21, 2007.

MATTOS, L.M. Alface crespa minimamente processada: embalagem sob diferentes sistemas de atmosfera modificada e armazenamento refrigerado. 2005. 151f. Tese (Doutorado em Ciência dos Alimentos) - Universidade de Lavras, MG.

MATTOS, L.M. et al. Qualidade de alface crespa minimamente processada armazenada sob refrigeração em dois sistemas de embalagem. Horticultura Brasileira, v.25, n.4, p.504-508, 2007. Disponível em: $<$ http://www.scielo.br/scielo.php?script=sci arttext\&pid=S0102- 05362007000400003>. Acesso em: 18 fev. 2015. doi: $10.1590 / \mathrm{S} 0102-05362007000400003$.

MORETTI, C.L. Panorama de processamento mínimo de frutas e hortaliças. In: Ed. Manual de processamento mínimo de frutas e hortaliças. Brasília: Embrapa Hortaliças e SEBRAE, 2007. p.25-40.

OLIVEIRA, A.C.B. et al. Divergência genética e descarte de variáveis em alface cultivada sob sistema hidropônico. Acta Scientiarum, v.26, n.2, p.211-217, 2004. Disponível em: <http:// periodicos.uem.br/ojs/index.php/ActaSciAgron/article/view/1894>. Acesso em: 01 jan. 2013. doi: 10.4025/actasciagron.v26i2.1894.

SIEGEL, B.Z. Plant peroxidases: an organism perspective. Plant Growth Regulation, v.12, p.303-312, 1993.

SOARES, R.M. et al. Ineficiência de Acibenzolar S-metil na indução de resistência de feijoeiro à murcha-de-curtobacterium. Fitopatologia Brasileira, v.29, p.373-377, 2004. Disponível em: $<$ http://dx.doi.org/10.1590/S0100-41582004000400001>. Acesso em: 01 jun.2013. doi: 10.1590/S0100-41582004000400002.

STEEL, R.G.D.; TORRIE, J.H. Principles and procedures of statistics. A biometrical approach. 2.ed.New York: McGraw-Hill Book, 1987.633p.

ZAGORY, D. Controlled and modified atmospheres. II. Advances in MAP. In: UCDAvis. Postharvest technology. Davis: Fresh-Cut products: Maintaining quality and safety, 2000. Seção 7b, p.4-5.

Ciência Rural, v.45, n.11, nov, 2015. 